\title{
Plateau iris
}

\author{
Íris em platô
}

\author{
Alberto Diniz Filho ${ }^{1}$ \\ SebastiãoCronemberger ${ }^{2}$ \\ Rafael Vidal Mérula ${ }^{3}$ \\ Nassim Calixto $^{4}$
}

\begin{tabular}{l} 
ABSTRACT \\
\hline The term plateau iris was first coined in 1958 to describe the iris \\
configuration of a patient. Two years later the concept of plateau iris was \\
published. In 1977, the plateau iris configuration was classically defined \\
as presurgical changes of an eye with a relative normal central anterior \\
chamber depth, flat iris by conventional biomicroscopy, but displaying \\
an extremely narrow or closed angle on gonioscopic examination. On the \\
other hand, the plateau iris syndrome was defined as an acute glaucoma \\
crisis in one eye with a relative normal central anterior chamber depth and \\
patent iridotomy on direct examination, presenting angle closure \\
confirmed by gonioscopic examination after mydriasis. In 1992, the \\
anatomic aspects of plateau iris were studied using ultrasound biomi- \\
croscopy. Finally, plateau iris has been considered an anatomic variant \\
of iris structure in which the iris periphery angulates sharply forward from \\
its insertion point and then again angulates sharply and centrally \\
backward, along with an anterior positioning of the ciliary processes seen \\
on ultrasound biomicroscopy. The clinical treatment of plateau iris \\
syndrome is carried out with topical use of pilocarpine. However, the \\
definitive treatment should be fulfilled by performing an argon laser \\
peripheral iridoplasty.
\end{tabular}

Keywords: Glaucoma, angle-closure; Anterior chamber/ultrasonography; Gonioscopy; Iris diseases/ultrasonography; Syndrome

\section{INTRODUCTION}

In general, the depth of the anterior chamber is well correlated with the width of the angle. However, in a few cases, the occurrence of narrow angle in eyes with anterior chamber of relatively normal depth and a relatively flat iris plane had been noted as early as $1940^{(1)}$.

Barkan found such a configuration in $20 \%$ of his patients, and mentioned that the angle was opened after iridectomy in most of them ${ }^{(2)}$. Higgit and Smith described two cases of angle-closure glaucoma in younger patients. These patients had a flat iris and a narrow angle secondary to an abrupt angulation at the root of the iris ${ }^{(3)}$. Chandler, in the same year, presented a patient with repeated intermittent angle-closure glaucoma despite a patent iridectomy who was successfully treated with pilocarpine ${ }^{(4)}$. Those cases were considered different from the ordinary cases of narrow angle glaucoma. They are particularly found in younger patients in whom a peripheral iridectomy is often ineffective. After this procedure no widening of the angle is found unlike what occurs in other cases of narrow angle glaucoma ${ }^{(5)}$.

Törnquist (1958) was the first to use the term plateau type of iris describing an acute case of glaucoma in a 44-year-old man with angleclosure glaucoma who had a normal anterior chamber depth, flat iris 
surface, which in its most peripheral part curved sharply backwards to produce a rather narrow angle ${ }^{(6)}$.

The concept of plateau iris was established in a publication dated 1960 by Shaffer; Kitazawa et al., (1970) described a case of a plateau iris ${ }^{(7-8)}$. Wand et al. (1977), studied eight patients who presented crisis of angle closure glaucoma after iridotomy ${ }^{(4)}$. In order to avoid confusion, they reported that the plateau iris syndrome (PIS) should be differentiated from the plateau iris configuration (PIC). PIC refers to a preoperative condition in which angle-closure glaucoma is gonioscopically confirmed, but the iris is flat and the anterior chamber is not axially shallow. In most cases, the angle-closure glaucoma due to PIC is not cured by a peripheral iridectomy. PIS refers to a postoperative condition in which a patent iridectomy has removed the relative pupillary block which is ordinarily important in causing angle closure (Figure 1), but confirmed angle closure is gonioscopically repeated without shallowing of the anterior chamber axially. PIS is rare compared to the PIC, which itself is not common.

In PIS, angle closure usually occurs in the early postoperative period but may occur long after iridectomy when the pupil dilates spontaneously or in response to mydriatic agents. Usually, it occurs in a younger age group than that of primary angle-closure glaucoma. PIS treatment is fulfilled with pilocarpine postoperatively as long as needed. This syndrome must be considered in the differential diagnosis when the intraocular pressure rises unexpectedly following a patent peripheral iridectomy ${ }^{(4,8)}$.

In the past, the anatomical basis for the plateau iris was unknown. The pathogenesis of PIS was speculative. Törnquist postulated that an anomaly in the structure or position of the ciliary body such as the contraction of the ciliary muscle would cause the narrowing or closing of the angle ${ }^{(5)}$. Barkan suggested a disproportionate size of the lens and abnormal narrowness of the perilental space, noting the fre-

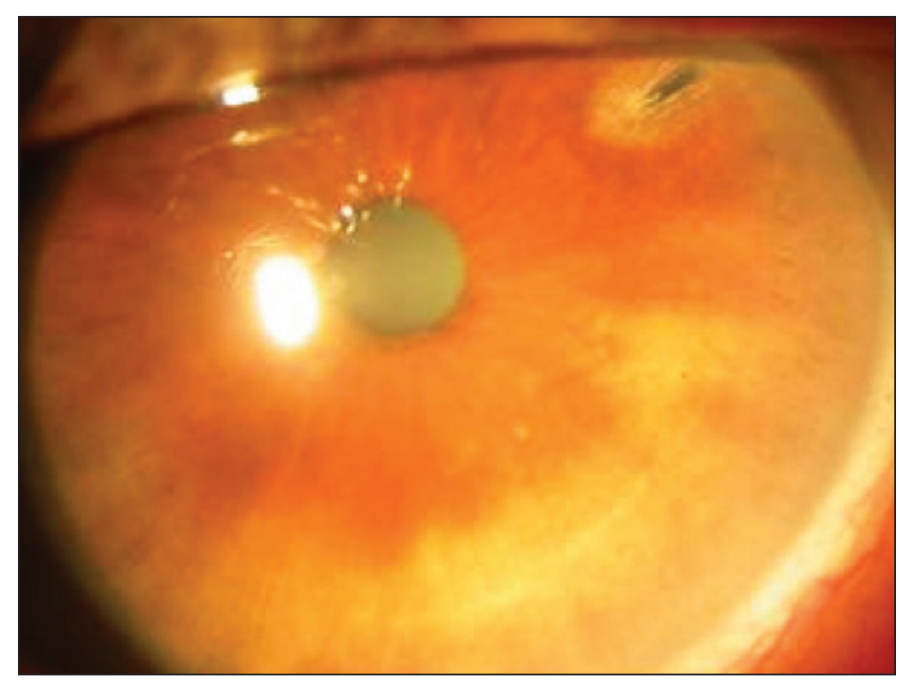

Figure 1 - Slit-lamp image of an eye of a patient with plateau iris syndrome showing the patent peripheral iridotomy (PI). quency with which the tips of the ciliary processes project anteriorly to the lens equator ${ }^{(2)}$. Chandler and Grant believed there is an anterior rotation of ciliary processes similar to what may occur in choroidal effusions or after scleral buckling surgery ${ }^{(9)}$.

Lowe believed that the anomaly was in the size and insertion of the iris root. The cases in which the iris root was anatomically short and the angle narrow, pupillary dilation might cause the most peripheral fold of iris to bunch into the angle, even after the elimination of pupillary block by iridectomy ${ }^{(10)}$.

In 1992, Ritch described two patients previously submitted to a laser iridectomy. In one case, with the elimination of the pupillary block component, the iris surface became flatter and the periphery of the iris appeared as a "high plateau" configuration, the surface of the iris at the point of angulation being nearly at the level of Schwalbe's line. In the other case, the angles remained appositionally closed to the upper border of the pigmented band of the trabecular meshwork ("mid plateau") (11).

The deepest point of indentation was not at the periphery of the iris, but at approximately two-thirds of the distance between the center of the pupil and the iris root. From this point to the site of appositional closure, the peripheral iris rose again and significant pressure had to be applied to the cornea with the Zeiss lens in order to open the angle. If the angle opened, the entire structure from the deepest point of indentation to the peripheral iris would rotate forward as a unit, suggesting that the ciliary processes were either anteriorly rotated, anteriorly positioned, or abnormally large ${ }^{(11)}$.

\section{PURPOSE}

To evaluate and promote literature review on PIC and PIS: history, epidemiology, clinical diagnosis, ultrasound biomicroscopy (UBM) features and treatment, besides the relationship between these entities and the malignant glaucoma.

\section{METHODS}

Literature review was made, PIS and PIC related studies were examined from 1940 to 2008 through MEDLINE, LILACS and BIREME Internet search sites, and further research was made at the Faculty of Medicine of the Federal University of Minas Gerais library.

\section{Epidemiology}

Patients with PIC who develop angle-closure glaucoma are generally younger than those with primary angle-closure glaucoma.

The first study found that patients with PIS have a mean age of 39.6 years at first presentation (range, 22-49 years). No gender predisposition has been observed ${ }^{(4)}$. 
Angle-closure glaucoma is rare in children and young adults; only scattered cases associated with specific clinical entities have been reported ${ }^{(12)}$.

In a retrospective study that evaluated the angle closure etiology in young patients, PIS was responsible for the highest frequency of closure revealed in $35(52.2 \%)$ out of the 67 patients with angle closure glaucoma. Patients with PIS were mostly women ( $74.3 \%$ ), young (34.9 years old on average), less hypermetropic than the patients with pupillary block who, very often, have a family history of angle closure glaucoma. Excepting younger patients, some elements of the pupillary block are present ${ }^{(12)}$.

In one study that was designed to ascertain the prevalence of PIS in the first-degree relatives of patients with PIS, among the 10 patients whose living first-degree relatives were screened, 5 families with at least 1 additional first-degree family member having PIS were found. In this study, all patients with PIS were followed over a 5-year period. Some families had more than 1 member with PIS. The pattern of inheritance of PIS seems to be autosomal dominant with incomplete penetrance ${ }^{(13)}$.

Another study was initially based on chart analysis, in which 30 of 137 individuals were diagnosed with PIS (22\%). After the clinical review, 34 additional patients suffered from PIS as the underlying cause of persistent angle closure symptoms. The prevalence of clinically confirmed PIS in that population with recurrent angle closure symptoms in spite of patent iridotomy or iridectomy was $54 \%$. The occurrence of PIS in the complete study was $47 \%^{(14)}$. The results of this study concur with the findings of the retrospective study that evaluated the angle closure etiology in young patients ${ }^{(12,14)}$. Both studies emphasize that the etiology of angle closure in the relatively young patients differs from the etiology of an older population, with a clear female prevalence in both ${ }^{(12,14-15)}$.

A recent cohort cross-sectional study was published determining the prevalence of plateau iris in primary angle closure suspects (PACSs) using UBM. Subjects over the age of 50 years diagnosed as PACSs were randomized to undergo laser peripheral iridotomy (PI) in one eye. UBM was performed before and a week after PI. UBM images were qualitatively assessed using standardized criteria. Two hundred five subjects were enrolled; UBM images of 167 subjects were available for analysis. Plateau iris was found in 54 out of 167 (32.3\%) PACS eyes after PI. Plateau iris was most commonly observed in the superior and inferior quadrants. Using standardized UBM criteria, plateau iris was found in about a third of PACS eyes after $\mathrm{PI}^{(16)}$.

The fact that PIC cannot be observed but in only one or two quadrants of the eye is a concern about this study for it contradicts previous reports. Moreover, authors have reported a very high percentage $(32.3 \%)$ of plateau iris in PACS eyes after PI. This is not the clinical experience, nor that of UBM reported by literature(4,14,17-18).

A retrospective study analyzing the UBM images of 228 Brazilian patients was performed to present the prevalence and morphometric findings of PIC on eyes of glaucomatous patients with narrow angle or primary angle-closure glaucoma. In all eyes with PIC the following were assessed: the central corneal thickness (CCT); the anterior chamber depth (ACD); the angle opening distance at $500 \mu \mathrm{m}$ of the scleral spur (AOD500); the peripheral iris thickness (IT) at $500 \mu \mathrm{m}$ of the scleral spur; the iris-ciliary process distance (ICPD); the trabecular-ciliary process distance (TCPD) and the area of recess of the angle (ARA) taken in the temporal position. One hundred and seventy-one (75\%) out of 228 patients were female and $57(25 \%)$ were male. Twenty-two patients (37 eyes) had PIC corresponding to the prevalence of $9.6 \%$. Twentythree $(62.2 \%)$ eyes of 15 patients had complete PIC and 14 eyes from 7 patients $(37.8 \%)$ had incomplete PIC. Two patients $(9.1 \%)$ had PIS in both eyes. Seventeen $(77.3 \%)$ out of 22 patients with PIC were female and 5 (22.7\%) were male. No statistically significant difference was found between the morphometric findings of the eyes with complete and incomplete PI except for the ICPD. However, when the comparison between the former and those of normal eyes was made, all parameters of the eyes with PI showed lower values, the statistical differences being highly significant with the exception of CCT and IT. The prevalence of PI was of $9.6 \%$, being much higher in females $(77.3 \%)$ with a statistically significant difference. No statistically significant difference was found between the morphometric findings of complete and incomplete PI, except for ICPD. However, all the measures of the eyes with PI showed lower values when compared to those of normal eyes, the statistical differences being highly significant with the exception of CCT and $\mathrm{IT}^{(17)}$.

PIC, as well as PIS, is an uncommon entity, but the syndrome is rarer than PIC. On the other hand, PIS is the most common underlying etiology of angle closure in relatively young patients, especially in women ${ }^{(15)}$.

\section{Clinical diagnosis}

Plateau iris has been considered an anatomic variant of iris structure in which the iris root angulates sharply forward from its insertion point and then again angulates sharply and centrally. The surface of the iris appears relatively flat, giving the iris the appearance of a plateau in saggital section ${ }^{(11)}$.

The clinical diagnosis of PIS requires iridotrabecular apposition in the presence of a patent iridectomy in darkroom gonioscopy; peripheral iris anteriorly and centrally angled; a flat or slightly convex iris, and the sign of a double hump that means the formation of anterior concavity of the iris at the lens' equator level with the indentation gonioscopy $^{(18)}$. This gonioscopic indentation finding in eyes with plateau iris is not observed in eyes with primary angleclosure from relative pupillary block.

Complete and incomplete plateau iris are defined by the level of the iris relative to Schwalbe's line and the structures of the angle wall.

It is assumed that the lens of these eyes is proportionally thicker than that of normal eyes, or of younger patients. If this 
is true, the thicker lens associated with the anatomic abnormality of the ciliary body's positioning can play a very important role in the acute crisis of glaucoma by pupillary dilation. This hypothesis is supported by the fact that in eyes with PIC and cataract, from which the cataract has been removed, the abnormal positioning of the ciliary body persists, but an increase of the anterior chamber depth takes place, as well as the widening of the angle, which prevents the installation of an acute crisis of glaucoma ${ }^{(18)}$.

\section{Ultrasound biomicroscopy (UBM)}

The UBM is an image examination method that has been used to clarify many diseases of the anterior segment for more than a decade ${ }^{(19-2)}$. The UBM enabled specialists to anatomically establish the so-called PIC and explain the PIS mechanism that occurs in some eyes ${ }^{(11,23)}$. Using the UBM, Pavlin et al. studied the anatomic changes of the anterior segment in eight patients with a clinical diagnosis of PIS ${ }^{(23)}$. In all of them, the ciliary processes were situated anteriorly as compared to the position in normal subjects and in patients with angle closure glaucoma caused by pupillary block. The ciliary processes give structural support to peripheral iris avoiding its withdrawal from the trabecular band after iridotomy. Thus, the anatomic change found in the eyes of these patients is an anterior angulation of the peripheral iris in its insertion in the ciliary body. In some cases, the iris root is short and thick and inserted in a more anterior position in the ciliary body, anteriorization of the ciliary processes also occurring. There is, thus, an important narrowing of the angle even though the central depth of the anterior chamber is normal ${ }^{(18)}$.

Ultrasound biomicroscopy plays a fundamental role in the PIC diagnosis. The above-mentioned anatomic abnormality of the ciliary body, only suspected by means of conventional biomicroscopic examination, especially by gonioscopy, is definitely confirmed by that imaging method ${ }^{(23)}$.

Plateau iris was defined by the presence of an anteriorly directed ciliary body, an absent ciliary sulcus, a steep iris root from its point of insertion followed by a downward angulation from the corneoscleral wall, presence of a central flat iris plane, and irido-angle contact ${ }^{(16,23)}$.

The importance of the diagnosis of PIC by UBM resides in the fact that preventive measures may be adopted in order to avoid the installation of an eventual acute crisis of glaucoma or its repetition (PIS) despite the presence of a patent iridotomy.

Figure 2 depicts the relation of the plateau iris position (the level of the iris relative to Schwalbe's line and the structures of the angle wall) and the possibility of acute crisis of glaucoma liable to occur spontaneously or after mydriasis ${ }^{(24)}$ and Figure 3 shows the image of a PIS patient assessed by UBM.

A review of measures of the ACD in 318 eyes of 318 patients who had been diagnosed by UBM as having either pupillary block or PIS was performed. Patients with PIS were previously submitted to an iridotomy. The ACD was measured axially from the internal corneal surface to the lens surface using the ultrasound instrument's internal measuring capability. Review of the literature suggests that patients with PIS have a normal or deeper axial ACD compared with pupillary block. However, in this study it was found that the ACD associated with PIS is shallower than normal and also shallower than in pupillary block ${ }^{(25)}$. Another study agrees with shallower ACD both in PIC and PIS patients ${ }^{(17)}$.

Ultrasound biomicroscopy can reveal classic features of PIS but also shows multiple neuroepithelial cysts of the ciliary body. PIS may be associated with multiple ciliary body cysts, the so-called pseudoplateau iris $^{(26)}$.

Ultrasound biomicroscopy has also been used to perform a darkroom provocative test, which provides information on whether the angle anatomically closes in the $\operatorname{dark}^{(27)}$.

A cohort study of Brazilian patients using UBM assessed the presence of nonpupil block mechanisms and appositional angle closure after PI. The study included 22 open angle eyes and 31 eyes with occludable angles on gonioscopy. Radial

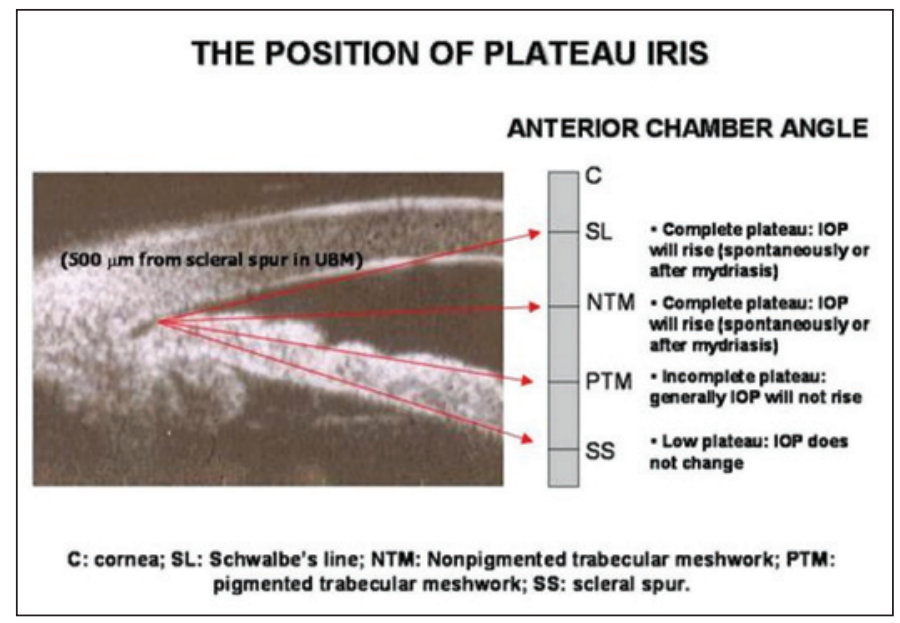

Figure 2 - Position and types of plateau iris in relation to the IOP rising possibility. Modified from: Ritch R, Lowe RF. Angle-closure glaucoma - clinical types. In: Ritch R, Shields MB, Krupin T, editors. The glaucomas. Saint Louis: Mosby; 1996. p.821-40.

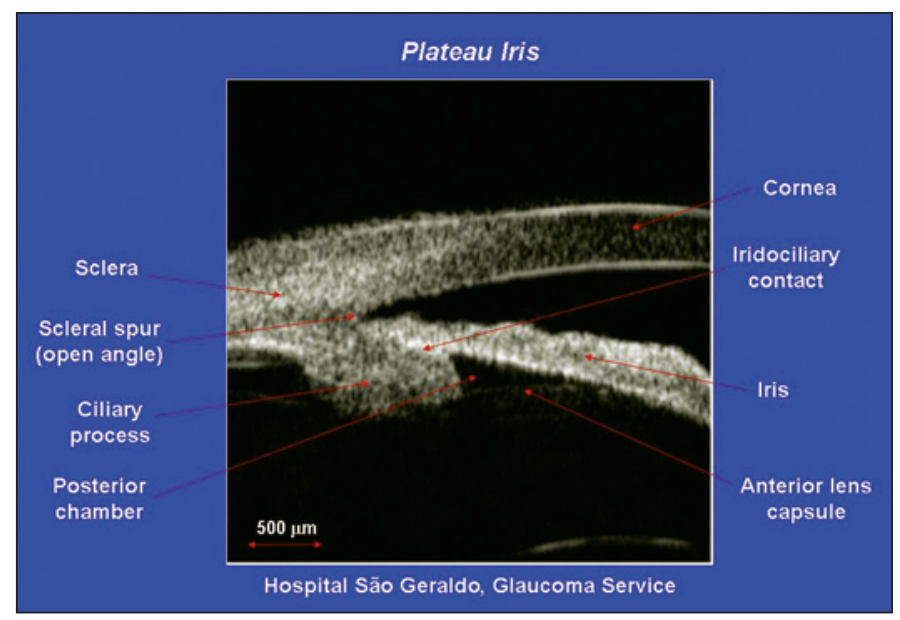

Figure 3 - Schematic UBM picture showing the structures assessable in plateau iris. 
scans through a typical ciliary process were obtained in both light and dark conditions, at inferior and superior positions. Long ciliary processes with no ciliary sulcus were determined on the basis of a reference line drawn perpendicular to the iris plane passing through a point located $750 \mu \mathrm{m}$ from the scleral spur. Trabecular-ciliary process distance was measured on the inferior quadrant of the UBM images. After PI, $52 \%$ of occludable angle eyes had appositional angle closure in both quadrants. We also observed this finding in $14 \%$ and $23 \%$ of the control eyes (at inferior and superior UBM images, respectively). A long ciliary process with no ciliary sulcus was observed in $61 \%$ of occludable angle eyes, and also in $32 \%$ of control eyes (inferior UBM images). Control eyes had longer TCPD than occludable angle eyes $(\mathrm{P}<0.001)$. The UBM finding of long ciliary processes associated with the absence of ciliary sulcus is not necessarily related to an anterior positioning of the ciliary processes ${ }^{(28)}$.

\section{Treatment}

The clinical treatment of PIC and PIS could be done with topical use of pilocarpine. However, the definitive treatment is made performing an argon laser peripheral iridoplasty (ALPI).

In a prospective study, changes in angle configuration associated with dark, light, and pilocarpine administration in PIS were reported. In 10 eyes of 10 patients with PIS and persistent narrow angles after patent PI, UBM was used to image variations in angle opening, IT, and TCPD. Measurements were taken in the dark, in full room light, and after administration of pilocarpine $2 \%$. In PIS, anteriorly located ciliary processes support the periphery of the iris. Changes in angle opening in dark and light are solely related to changes in iris thickness. Pilocarpine produces iris thinning and is an effective drug for opening the angle ${ }^{(27)}$.

The PI does not avoid the repetition of the glaucoma crisis because it does not change the anatomy of the anterior segment in patients with $\mathrm{PIC}^{(27,29)}$. Therefore, the repetition of acute crisis of glaucoma despite the presence of a patent iridotomy is the diagnostic seal of the PIS. On the other hand, ALPI has been highly effective in the elimination of the appositional residual closure caused by PIS $^{(30-32)}$. An alternative to ALPI would be the constant use of pilocarpine on eyes with PIC. Generally, in ALPI, 20 to 24 spots ( 5 to 6 per quadrant) are made, power 200 to 400 milliwatts, duration 0.1 to 0.5 seconds over 360 degree circumference as shown in Figure $4^{(31-32)}$.

A retrospective study was performed to document the long-term effect of ALPI in eyes with PIS. All PIS treated patients by ALPI with a follow-up of 6 or more years were retrospectively reviewed. A total of 26 ALPI procedures were performed in 23 eyes of 14 patients. The angle in 20 of 23 (87.0\%) eyes remained open throughout the entire follow-up period after only 1 treatment with ALPI. In 3 eyes, there was gradual re-closure of the angle 5 to 9 years after initial ALPI, but they were readily reopened and maintained open by a single repeat treatment. No filtration surgery was necessary in any eye during follow-up. ALPI is highly effective in eliminating residual appositional closure after PI caused by PIS. The effect is maintained for years, although a small proportion of patients might require retreatment ${ }^{(32)}$.

The presence of PIS in eyes presenting sudden and unexpected IOP increase after the performance of patent peripheral iridotomy for PACG treatment should be suspected. Clinically speaking, to prevent the installation of the PIS, the best measures are the constant use of pilocarpine and the preventive care before and after pupillary dilation of the eyes with PIC.

\section{Plateau iris and malignant glaucoma}

Some studies report that in malignant glaucoma there is an anterior rotation of the ciliary body with the disappearance of the ciliary sulcus on UBM examination similar to what is observed in PIC.

To provide evidence for diagnosing malignant glaucoma, as well as for elucidating the pathogenetic mechanism of the disease, UBM is a useful tool. The anterior segment of three patients with postoperative malignant glaucoma were examined by UBM regarding the state before operation, the state of the opposite eye, and the state after the release of the ciliolenticular block ${ }^{(33)}$. Slit-like anterior chamber angle and anteriorly positioned ciliary body were observed in all 3 cases, which were identical to those that Pavlin reported in 8 cases with PIS. UBM seems to be an important preoperative examination to evaluate the risk of malignant glaucoma and to determine which surgical procedure and postoperative ma-

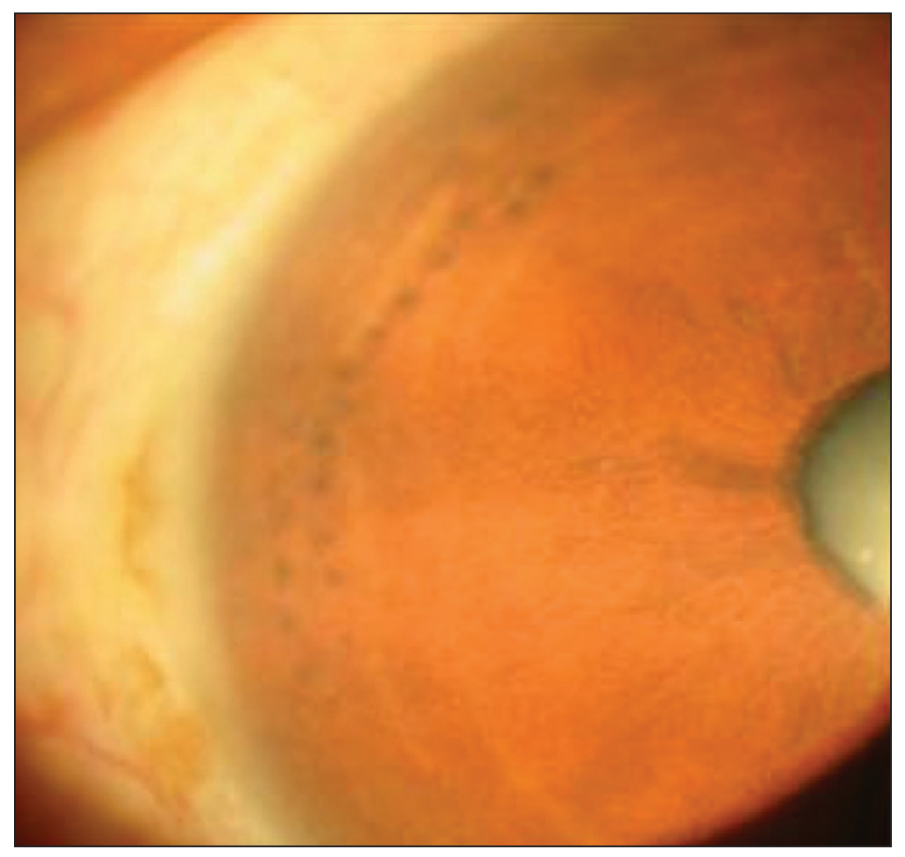

Figure 4 - Slit-lamp image of an eye of a patient with plateau iris configuration treated by argon laser peripheral iridoplasty (ALPI). Notice the marks of argon laser at the periphery of iris. 
nagement is proper. The preoperative configuration of the ciliary body may be associated with the onset of malignant glaucoma in some patients with chronic angle-closure glaucoma or narrow angle ${ }^{(33)}$.

Therefore, studies using UBM are needed to better understand the role of PIC in the etiopathogeny of the malignant glaucoma ${ }^{(33-35)}$.

\section{CONCLUSION}

Prospective longitudinal studies with large samples aiming at the study and comparison of the morphometric findings in eyes of normal patients, suspected or confirmed glaucoma patients, with narrow angle or primary angle-closure glaucoma, with or without PIC and their relationship with malignant glaucoma are required to determine the clinical significance of the actual findings in PIC and PIS patients, and to better understand and manage them.

\section{RESUMO}

O termo íris em platô foi primeiramente inventado em 1958 para descrever a configuração da íris de um paciente. Dois anos depois o conceito de íris em platô foi publicado. Em 1977, a configuração de íris em platô foi classicamente definida como alterações pré-cirúrgicas de um olho com uma profundidade de câmara anterior relativamente normal, íris plana pela biomicroscopia convencional, mas mostrando um ângulo extremamente estreito ou fechado pela gonioscopia. Por outro lado, a síndrome de íris em platô foi definida como uma crise de glaucoma agudo em um olho com uma profundidade de câmara anterior relativamente normal e uma iridectomia patente ao exame direto, apresentando fechamento angular confirmado pela gonioscopia após midríase. Em 1992, as alterações anatômicas dessa anomalia foram estudadas utilizando a biomicroscopia ultra-sônica. Finalmente, a configuração de íris em platô refere-se à alteração anatômica em que há a angulação anterior da periferia da íris, do seu ponto de inserção na parede do ângulo iridocorneal e centralmente, com anteriorização dos processos ciliares, diagnosticada pela biomicroscopia ultra-sônica. O tratamento clínico da síndrome da íris em platô pode ser feito com a administração tópica de pilocarpina, porém o tratamento definitivo é feito com a iridoplastia periférica com o laser de argônio.

Descritores: Glaucoma de ângulo fechado; Câmara anterior/ ultra-sonografia; Gonioscopia; Doenças da íris/ultra-sonografia; Síndrome

\section{REFERENCES}

1. Gradle HS, Sugar HS. Concerning the chamber angle. III. A clinical method of goniometry. Am J Ophthalmol. 1940;23:1135-9.
2. Barkan O. Narrow-angle glaucoma. Pupillary block and the narrow-angle mechanism. Am J Ophthalmol. 1954;37(3):332-50.

3. Higgitt A, Smith R. Reading test in glaucoma. Br J Ophthalmol. 1955;39 (2): 103-8.

4. Wand M, Grant WM, Simmons RJ, Hutchinson BT. Plateau iris syndrome. Trans Sect Ophthalmol Am Acad Ophthalmol Otolaryngol. 1977;83(1):122-30.

5. Lowe RF. Plateau iris. Aust J Ophthalmol. 1981;9(1):71-3.

6. Törnquist R. Angle-closure glaucoma in an eye with a plateau type of iris. Acta Ophthalmol (Copenh). 1958;36(3):419-23.

7. Kitazawa K, Nakamura Y, Nakamura C. [Case of plateau iris]. Ganka. 1970;12(11):939-43. Japanese.

8. Shaffer RN. Gonioscopy, ophthalmoscopy and perimetry. Trans Am Acad Ophthalmol Otolaryngol. 1960;64:112-27.

9. Chandler PA, Grant WM. Lectures on Glaucoma. Philadelphia: Lea and Febiger, 1965.

10. Lowe RF. Primary angle-closure glaucoma. Postoperative acute glaucoma after phenylephrine eye-drops. Am J Ophthalmol. 1968;65(4):552-4.

11. Ritch R. Plateau iris is caused by abnormally positioned ciliary processes. J Glaucoma. 1992;1(1):23-6.

12. Ritch R, Chang BM, Liebmann JM. Angle closure in younger patients. Ophthalmology. 2003;110(10):1880-9. Review.

13. Etter JR, Affel EL, Rhee DJ. High prevalence of plateau iris configuration in family members of patients with plateau iris syndrome. J Glaucoma. 2006;15 (5):394-8.

14. Stieger R, Kniestedt C, Sutter F, Bachmann LM, Stuermer J. Prevalence of plateau iris syndrome in young patients with recurrent angle closure. Clin Experiment Ophthalmol. 2007;35(5):409-13.

15. Ritch R, Dorairaj S. Plateau iris syndrome in younger patients. Clin Experiment Ophthalmol. 2007;35(5):399-400.

16. Kumar RS, Baskaran M, Chew PT, Friedman DS, Handa S, Lavanya R, et al. Prevalence of plateau iris in primary angle closure suspects. an ultrasound biomicroscopy study. Ophthalmology. 2007;115(3):430-4.

17. Cronemberger S, Diniz Filho A, Ferreira DM, Calixto N. Prevalence of plateau iris configuration and morphometric findings with narrow angle or primary angle-closure glaucoma ou ultrasound biomicroscopic examinations. Invest Ophthalmol Vis Sci. 2007;48:E-Abstract 3863.

18. Tran HV, Liebmann JM, Ritch R. Iridociliary apposition in plateau iris syndrome persists after cataract extraction. Am J Ophthalmol. 2003;135(1):40-3.

19. Pavlin CJ, Harasiewicz K, Sherar MD, Foster FS. Clinical use of ultrasound biomicroscopy. Ophthalmology. 1991;98(3):287-95.

20. Pavlin CJ, Foster FS: Ultrasound biomicroscopy of the eye. New York: Springer; 1995.

21. Cronemberger S, Marigo FA, Calixto N. Biomicroscopia ultra-sônica. In: Yamane R, editor. Semiologia ocular. Rio de Janeiro: Cultura Médica; 2003. p.367-85.

22. Pavlin CJ, Harasiewicz K, Foster FS. Ultrasound biomicroscopy of anterior segment structures in normal and glaucomatous eyes. Am J Ophthalmol. 1992;113(4):381-9. Comment in: Am J Ophthalmol. 1992;114(4):516-7.

23. Pavlin CJ, Ritch R, Foster FS. Ultrasound biomicroscopy in plateau iris syndrome. Am J Ophthalmol. 1992;113(4):390-5.

24. Ritch R, Lowe RF. Angle-closure glaucoma - clinical types. In: Ritch R, Shields MB, Krupin T, editors. The glaucomas. Saint Louis: Mosby; 1996. p. $821-40$.

25. Mandell MA, Pavlin CJ, Weisbrod DJ, Simpson ER. Anterior chamber depth in plateau iris syndrome and pupillary block as measured by ultrasound biomicroscopy. Am J Ophthalmol. 2003;136(5):900-3.

26. Azuara-Blanco A, Spaeth GL, Araujo SV, Augsburger JJ, Terebuh AK. Plateau iris syndrome associated with multiple ciliary body cysts. Report of three cases. Arch Ophthalmol. 1996;114(6):666-8.

27. Pavlin CJ, Foster FS. Plateau iris syndrome: changes in angle opening associated with dark, light, and pilocarpine administration. Am J Ophthalmol. 1999;128(3):288-91.

28. Sakata LM, Sakata K, Susanna R Jr, Sakata VM, Hatanaka M, Trancoso L, et al. Long ciliary processes with no ciliary sulcus and appositional angle closure assessed by ultrasound biomicroscopy. J Glaucoma. 2006;15(5):371-9.

29. Polikoff LA, Chanis RA, Toor A, Ramos-Esteban JC, Fahim MM, Gagliuso DJ, et al. The effect of laser iridotomy on the anterior segment anatomy of patients with plateau iris configuration. J Glaucoma. 2005;14(2):109-13.

30. Walsh A, Pavlin C, Yamane R, Crema AS. Estudo do segmento anterior com biomicroscopia ultra-sônica em bloqueio pupilar. Rev Bras Oftalmol. 1995;54 (6):7-17.

31. Ritch R, Tham CC, Lam DS. Argon laser peripheral iridoplasty (ALPI): an update. Surv Ophthalmol. 2007;52(3):279-88. 
32. Ritch R, Tham CC, Lam DS. Long-term success of argon laser peripheral iridoplasty in the management of plateau iris syndrome. Ophthalmology. 2004;111(1):104-8.

33. Ueda J, Sawaguchi S, Kanazawa S, Hara H, Fukuchi T, Watanabe J, et al [Plateau iris configuration as a risk factor for malignant glaucoma]. Nippon Ganka Gakkai Zasshi. 1997;101(9):723-9. Japanese.
34. Tello C, Chi T, Shepps G, Liebmann J, Ritch R. Ultrasound biomicroscopy in pseudophakic malignant glaucoma. Ophthalmology. 1993;100(9):1330-4. Erratum in: Ophthalmology. 1993;100(12):1747.

35. Trope GE, Pavlin CJ, Bau A, Baumal CR, Foster FS. Malignant glaucoma Clinical and ultrasound biomicroscopic features. Ophthalmlogy. 1994;101(6): 1030-5.

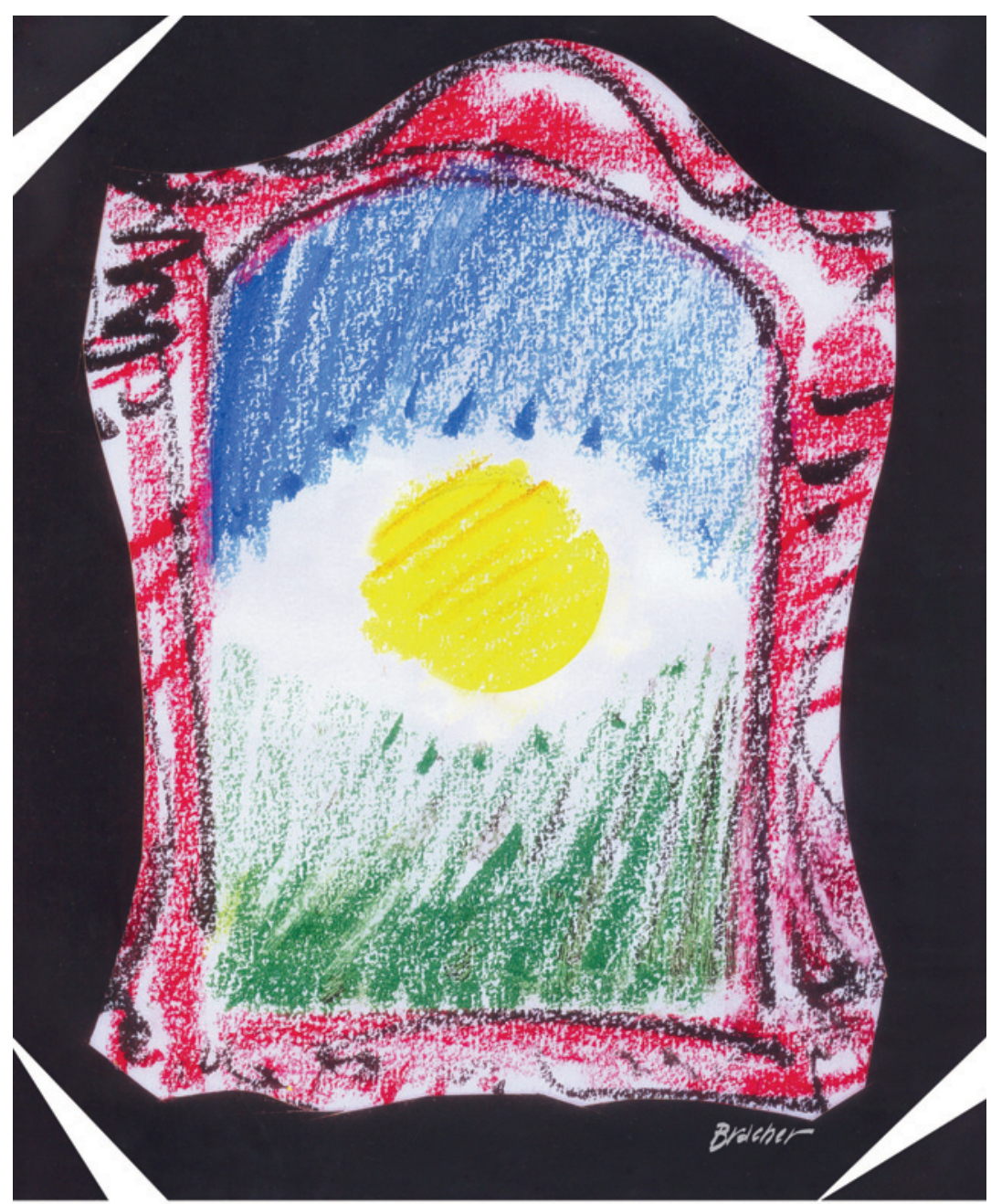

XXXV Congresso Brasileiro de Oftalmologia

Belo Horizonte - 24 a 27 de agosto de 2009 